\title{
OZAKI'S INEQUALITY AND UMEZAWA'S CONDITION FOR MULTIVALENT FUNCTIONS
}

\section{MAMORU NUNOKAWA AND JANUSZ SOKÓ£}

Abstract. Let $f(z)$ be analytic in $|z|<R$, continuous on $|z|=R$ and $f^{\prime}(z) \neq 0$ on $|z|=R$. Then holds Ozaki's inequality that the total variation of $\arg \{f(z)\}$ on $|z|=R$ is not more than the total variation of $\arg \{\mathrm{d} f(z)\}$ on $|z|=R$. Here we consider also Umezawa's condition that

$$
-\frac{\alpha}{2 \alpha-3}<1+\mathfrak{R e} \frac{z f^{\prime \prime}(z)}{f^{\prime}(z)}<\alpha \quad|z|<1
$$

follows the univalence of $f(z)$ in $|z|<1$. In this paper we extended these results for multivalent functions.

Mathematics subject classification (2010): Primary 30C45, Secondary 30C80.

Keywords and phrases: Univalent functions, starlike, convex, starlike of order alpha.

\section{REFERENCES}

[1] S. N. Kudryashov, On some criteria of schlichtness of analytic functions, (Russian), Mat. Zmetki 13 (1973) 359-366.

[2] S. S. Miller, P. T. Mocanu, On some classes of first-order differential subordinations, Michgan Math. J. 32 (1985) 185-195.

[3] K. NoshiRo, On the theory of schlicht functions, J. Fac. Sci. Hokkaido Univ. Jap. 2 (1) (1934-35) $129-135$

[4] M. Nunokawa, On the theory of multivalent functions, Tsukuba J. Math. 11 (2) (1987) 273-286.

[5] M. NunoKaWA, A note on multivalent functions, Tsukuba J. Math. 13 (2) (1987) 453-455.

[6] M. NunOKAWA, J. SoKó£, On multivalent starlike functions and Ozaki condition, submitted to Complex Variables and Elliptic Equations, https://doi.org/10.1080/17476933.2017.1419209.

[7] M. NUNOKAWA, J. SoKóŁ, On some conditions for schlichtness of analytic functions, (submitted).

[8] M. NunoKawa, J. Sokó£, On multivalent functions in the unit disc, Tsukuba J. Math. 41 (2) (2017) 251-263.

[9] M. Nunokawa, N. E. Cho, O. Kwon, J. SokóŁ, An improvement of Ozaki's p-valent condition, Acta Math. Sinica 32 (4) (2016) 406-410.

[10] S. OGAWA, Some criteria for univalence, J. Nara Gakugei Univ. 10 (1) (1961) 7-12.

[11] S. OZAKI, On the theory of multivalent functions, Sci. Rep. Tokyo Bunrika Daigaku Sect. A 2 (1935) $167-188$.

[12] S. OzaKi, On the theory of multivalent functions II, Sci. Rep. Tokyo Bunrika Daigaku Sect. A 4 (1941) 45-87.

[13] G. M. ShaH, On holomorphic functions convex in one direction, J. Indian Math. Soc. 37 (1973) 257-276.

[14] T. UmeZawa, Analytic functions convex in one direction, J. Math. Soc. Japan 4 (2) (1952) 194-202.

[15] T. UmeZawa, On the theory of univalent functions, Tohoku Math. J. 7 (3) (1955) 212-228.

[16] S. WARSCHAWSKI, On the higher derivatives at the boundary in conformal mapping, Trans. Amer. Math. Soc. 38 (1935) 310-340. 